\title{
Triceps to biceps transfer for restoration of elbow flexion following upper brachial plexus injury
}

\author{
Pothula Durga Prasada Rao, Rayidi Venkata Koteswara Rao, R. Srikanth \\ Department of Plastic Surgery, Nizam's Institute of Medical Sciences, Hyderabad, Telangana, India
}

Address for correspondence: Dr. Pothula Durga Prasada Rao, Department of Plastic Surgery, Nizam's Institute of Medical Sciences, Hyderabad, Telangana, India. E-mail: pothuladp@gmail.com

\section{ABSTRACT}

Introduction: Upper brachial plexus injury in adults causes loss of elbow $\mathrm{fl}$ exion; when the primary nerve surgery has failed or the patient seeks treatment after 12 months of injury and pedicled muscle transfers are required. Most commonly, the latissimus dorsi or the Steindler flexorplasty is used. Material and Methods: We have transferred one of the heads of triceps muscle to restore the elbow flexion in such cases. In addition to return of elbow flexion, extension of elbow following surgery is retained. Ten patients suffering from upper brachial plexus injuries underwent transfer of one head of triceps to biceps tendon between December 2011 and August 2015. Results: The recovery of elbow flexion was Grade 5 in 1, Grade 4 in 4 and Grade 3 in 2; only three of the ten patients had no functionally useful elbow flexion. Seven of the ten patients had an adequate elbow extension following the procedure.

\section{KEY WORDS}

Loss of elbow flexion; pedicled muscle transfer; triceps muscle; upper brachial plexus injury

\section{INTRODUCTION}

ure upper brachial plexus injury involves only the C5 and C6 roots. This leads to loss of shoulder abduction and elbow flexion; the loss of elbow flexion is due to denervation of biceps and brachialis muscles. Shoulder adduction, elbow extension and wrist dorsiflexion are retained as there is an intact $\mathrm{C} 7$ root contribution. Restoration of elbow flexion is a priority to enable hand-to-mouth activities. ${ }^{[1]}$

In adult upper plexus when the proximal roots are available, intraplexal neurotisation is done with sural

\begin{tabular}{|l|l|}
\hline \multicolumn{2}{|c|}{ Access this article online } \\
\hline Quick Response Code: & Website: \\
\hline & www.ijps.org \\
\cline { 2 - 2 } & DOI: \\
\hline
\end{tabular}

nerve grafts; in the absence of proximal nerve roots, extraplexal neurotisers are used to get predictable return of elbow flexion and shoulder abduction. ${ }^{[2]}$

Distal targeted nerve transfers have now expanded the scope of primary nerve surgery even for cases presenting beyond 6 months after injury, and predictable return of elbow flexion can be expected after the Oberlin type of transfers. ${ }^{[3]}$

There is a chance of failure of primary nerve surgery, and patients occasionally present for primary treatment

This is an open access article distributed under the terms of the Creative Commons Attribution-NonCommercial-ShareAlike 3.0 License, which allows others to remix, tweak, and build upon the work non-commercially, as long as the author is credited and the new creations are licensed under the identical terms.

For reprints contact: reprints@medknow.com

How to cite this article: Rao PD, Rao RV, Srikanth R. Triceps to biceps transfer for restoration of elbow flexion following upper brachial plexus injury. Indian J Plast Surg 2017;50:35-42. 
beyond a period of 12 months after the injury. In such situations, the restoration of elbow flexion can reliably be done using pedicled functional muscle transfers. ${ }^{[4]}$ Free functional muscle transfers are more applicable in failure of primary nerve surgery in complete plexus injuries where there are no suitable local muscles available. ${ }^{[5]}$

The lattissimus dorsi muscle has been used for restoration of elbow flexion - both the unipolar and bipolar types of transfers. ${ }^{[6]}$ In the absence of a good lattissimus dorsi or as a preference, the other muscles that have been used are the common flexor group of muscles (Steindler flexorplasty),,$^{[7]}$ pectoralis major ${ }^{[8]}$ and the triceps. ${ }^{[9]}$

The available choice for restoration of elbow flexion implies advantages and disadvantages of individual procedures.

The earliest description of using the triceps has been for patients with loss of elbow flexion due to polio or arthrogryposis. ${ }^{[10]}$

We have transferred a part of the triceps muscle as a pedicled functional muscle transfer for restoration of elbow flexion in patients who had failed nerve surgery or had a late presentation.

\section{MATERIALS AND METHODS}

Ten patients with a diagnosis of upper brachial plexus injury underwent partial transfer of the triceps muscle for restoration of elbow flexion.

All these patients were operated in our Department of Plastic Surgery between December 2011 and August 2016.

The age range of the patients was $18-57$ years with a mean of 28 years; all were male.

All patients had a baseline clinical examination prior to surgery for assessment of the following [Figure 1]:

Shoulder abduction and adduction; elbow flexion and extension; wrist dorsiflexion and flexion; finger flexion and extension. Grading was done as per the Medical Research Council (MRC) scale, and any range of movement at the elbow if present was recorded. All patients had a pre-operative electromyoneurography (EMNG) study.

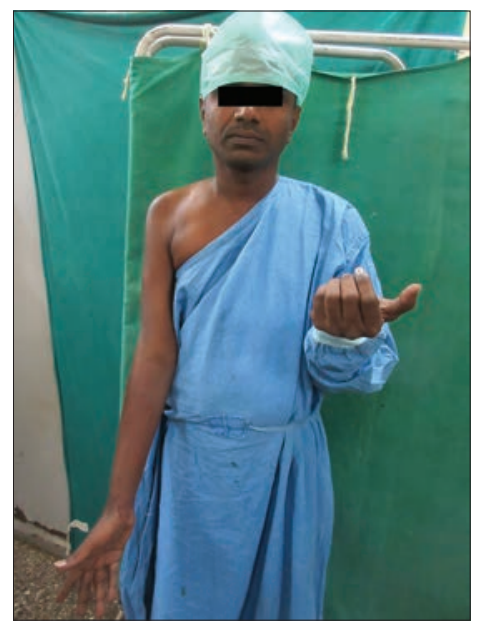

Figure 1: Pre-operative photograph showing lack of elbow flexion

\section{Inclusion criteria}

The pre-operative triceps grade was greater than or equal to MRC 4.

The pre-operative biceps grade was M0 to M2.

Assesment of the post-operative return of elbow flexion was graded as follows:

- Very good - Active range of motion (ROM) of $120^{\circ} / \mathrm{M} 4$

- Good - Active ROM of $80^{\circ}-120^{\circ} / \mathrm{M} 4$

- Fair - Active ROM of $70^{\circ}-120^{\circ} / \mathrm{M} 3$

- Failure - Active ROM of $<80^{\circ}$ and/MRC less than Grade 3.

\section{Surgical technique}

The surgery was done under general anaesthesia in the supine position; the use of muscle relaxant was deferred till complete isolation of the portion of the triceps tendon that was to be transferred.

In the first part of the surgery, the affected arm was placed over the chest so as to permit access and isolation of the relevant portion of the triceps muscle [Figure 2] and the second part was performed by keeping the shoulder in $90^{\circ}$ abduction with the entire upper limb on a hand trolley [Figure 3].

There were two incisions which were infiltrated with adrenaline saline 1:200,000; the first incision was along the centre of the back of the arm from the junction of upper and middle third down to the olecranon process. The second incision was on the lower anteromedial arm upto the cubital fossa to permit exposure of the biceps tendon. 
The posterior arm incision is used to expose the middle and lower thirds of the triceps; in the initial four cases, the medial half of the conjoint triceps was harvested with a sufficient length of tendon to permit suturing to the biceps tendon after transfer; this dissection was carried out proximally up to the the middle third of the arm carefully protecting the ulnar nerve. In the later six cases, the long head of the triceps was preferentially isolated proximally from the lateral head (as the medial head is distinct from both the lateral and the long heads in the distal third of the arm, it could be isolated and retained). ${ }^{[11]}$ [Figure 4]. The gap in the triceps tendon was sutured with 2 ' 0 ' polypropelene keeping the elbow in full extension. Since the long head arises from the infraglenoid tubercle, this permits a more direct route of transfer to the distal biceps.

The medial margin of the posterior skin incision was dissected off the neurovascular structures of the lower

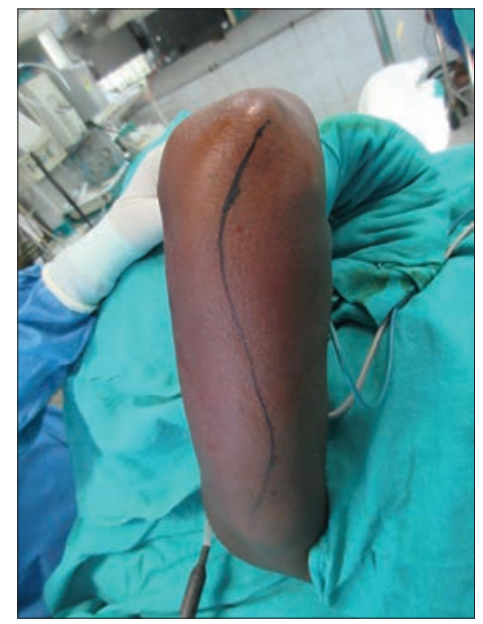

Figure 2: Markings for incisions for exposure of triceps

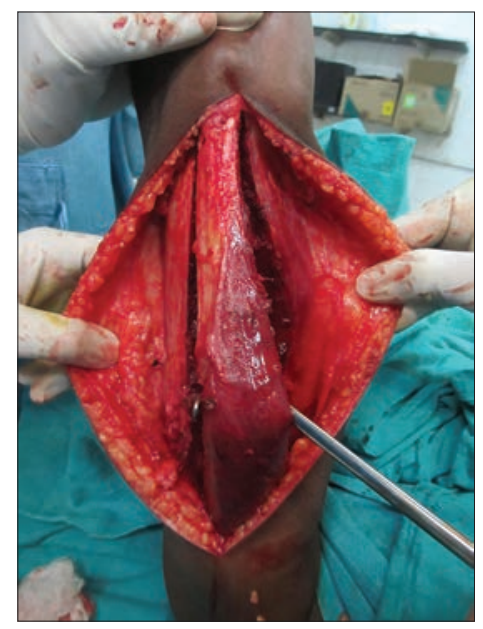

Figure 4: The separation of heads of triceps medial arm and the tunnel was developed subcutaneously to help rerouting the transected triceps anteriorly to the lower medial arm incision [Figure 5].

The posterior arm incision was closed in two layers over a suction drain and the upper limb was repositioned on a hand trolley. The tendon of the biceps was identified, the bicipital aponeurosis was cut off and muscle fibres of the biceps separated proximally from the tendon for 1 inch (to minimise the likelihood of post-operative adhesions).

The biceps tendon was transected (in cases with pre-operative $\mathrm{M} 0$ grade) and woven through the terminal end of the triceps in Pulvertaft fashion and suturing done using 2 ' 0 ' polypropelene keeping the elbow between $90^{\circ}$ and $100^{\circ}$ of flexion; in cases with pre-operative Grade M1 or M2, the suturing was done end to side to the biceps

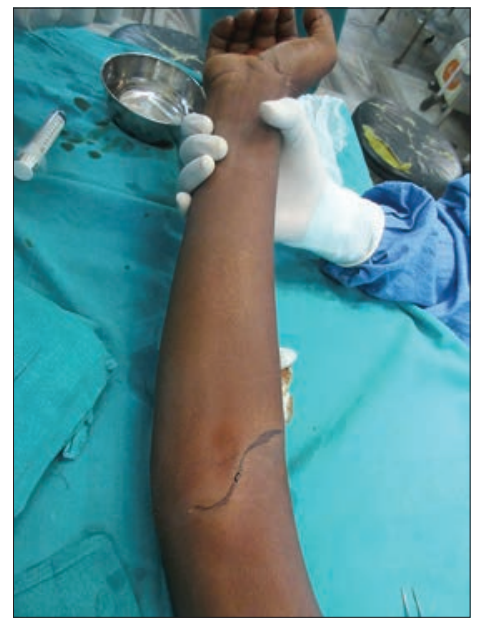

Figure 3: The marking on cubital fossa for exposure of tendon of biceps

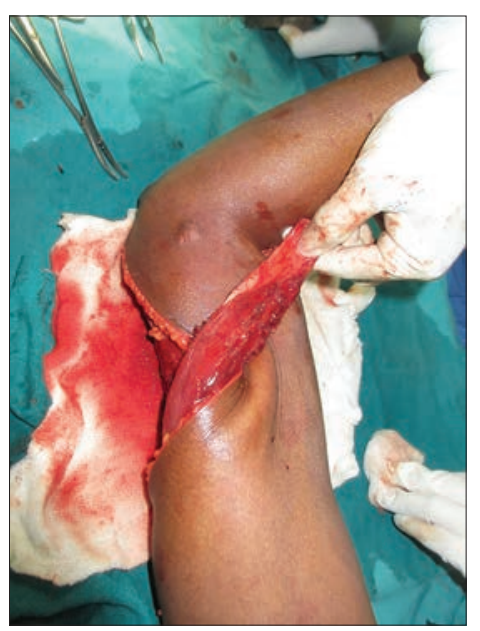

Figure 5: The reach of transferred head of triceps 
tendon using 2 ' 0 ' polypropelene keeping the elbow between $90^{\circ}$ and $100^{\circ}$ of flexion [Figure 6]. Skin incision was closed in two layers with a suction drain anteriorly and the limb immobilised in POP slab.

Assisted active ROM exercises (between $90^{\circ}$ and $120^{\circ}$ ) to permit active elbow flexion, within the limits of any pain, were started after $72 \mathrm{~h}$ with patients in lying down position. Drains were removed by the $5^{\text {th }}$ day and the patients were discharged between 10 and 12 days with ROM-assisted active elbow flexion exercises to be continued three times a day for 15 min each.

At 3 weeks, active ROM (between $75^{\circ}$ and $120^{\circ}$ ) was encouraged eliminating gravity and splintage continued; between 3 and 6 weeks, active extension was also permitted and the patients were encouraged to flex the elbow against gravity; the POP splint was replaced by an arm pouch sling to permit resting elbow flexion of $45^{\circ}$ for a further 3 weeks. By 12 weeks, all restraints had been removed and active ROM measurements were

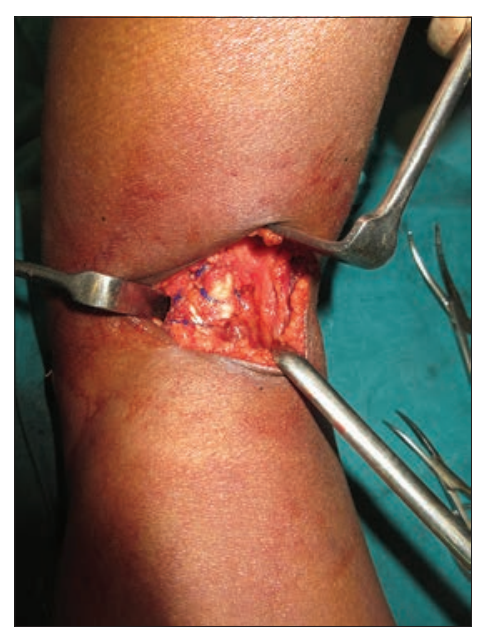

Figure 6: The attachment of transferred head of triceps with tendon of biceps taken to measure elbow flexion strength and elbow flexion range.

\section{RESULTS}

The total number of patients were 10; all were male, in the age range of $18-57$ years, with a mean age of 28 years [Table 1].

Three of these patients had undergone primary nerve surgery, and on follow-up examination between 12 and 18 months, there was M0 Grade in 1 and M1 Grade in 2 cases.

Seven patients came for treatment beyond 18 months of the injury and there was no power in the biceps (M0).

Shoulder function pre-operative two of three cases had shoulder abduction Grade 4 from earlier neurotisation; among seven cases with delayed presentation, five had no shoulder abduction and two had $<30^{\circ}$ active shoulder abduction.

\section{Surgical technique used}

Transfer of the medial portion of the conjoined triceps was used in four cases and transfer of the long head of triceps in six cases.

\section{Post-operative complications}

Haematoma in one case, with poor tensioning of the transfer (detected on removal of splintage at 3 months).

\section{DISCUSSION}

The use of pedicled functional muscle transfers for elbow flexion is an established method used in patients with failed primary nerve surgery or in patients who have

Table 1: Evaluation of return of function (between 3 and 6 months post-operatively)

\begin{tabular}{|c|c|c|c|c|c|c|}
\hline \multirow[t]{2}{*}{ Serial number } & \multirow[t]{2}{*}{ Age } & \multirow[t]{2}{*}{ Head of triceps } & \multicolumn{2}{|c|}{ Elbow flexion grade } & \multirow[t]{2}{*}{ Active ROM elbow flexion post-operative } & \multirow[t]{2}{*}{ Functional evaluation } \\
\hline & & & Pre-operative & Post-operative & & \\
\hline 1 & 27 & Medial & 0 & $4 / 5$ & 110 & Good \\
\hline 2 & 22 & Medial & 1 & $3 / 5$ & 100 & Good \\
\hline 3 & 33 & Medial & 0 & $2 / 5$ & - & Poor \\
\hline 4 & 18 & Medial & 0 & $2 / 5$ & - & Poor \\
\hline 5 & 23 & Long & 0 & $4 / 5$ & 130 & Very good \\
\hline 6 & 30 & Long & 0 & $3 / 5$ & 90 & Good \\
\hline 7 & 57 & Long & 1 & $2 / 5$ & - & Poor \\
\hline 8 & 22 & Long & 0 & $5 / 5$ & 140 & Very good \\
\hline 9 & 37 & Long & 0 & $4 / 5$ & 140 & Very good \\
\hline 10 & 22 & Long & 0 & $4 / 5$ & 100 & Good \\
\hline
\end{tabular}


beyond 12 months after injury late for treatment. In total, for plexus injuries, a free functional muscle transfer is necessary on account of absence of local muscle availability. ${ }^{[5]}$

Different muscles have been used as transfers for elbow flexion in partial plexus injuries. The latissimus dorsi muscle as unipolar or bipolar variants has been used for restoration of elbow flexion. Analysis of results reveals $75 \%$ return of flexion across a range between $60^{\circ}$ and $140^{\circ}$; the authors report that the results depend on rehabilitation. A flexion contracture of $10^{\circ}-15^{\circ}$ has also been reported by other authors. ${ }^{[12]}$

A review article of different techniques highlights the problems of the latissimus dorsi pedicled transfer for elbow flexion - clinical assessment of strength of this muscle is not very specific (inability to differentiate the action of the teres major) and any subclinical injury to the $\mathrm{C} 7$ root may downgrade the muscle strength leading to a poor result; the distal insertion of muscle tissue to biceps tendon is not comparable and long incisions are needed to execute the transfer. ${ }^{[13]}$ Among local muscle transfers for elbow flexion, surgical technique for partial triceps transfer was the easiest and permits early active ROM exercises for the elbow.

Eight of the ten patients underwent uni- or bi-polar latissimus dorsi transfer for sequelae of upper plexus injuries; 6 of 8 Grade 4 and 2 had Grade 3 preoperatively; 4 of 8 did not acquire useful elbow flexion; all 4 needed further reefing of distal end of the transfer and an additional Steindler procedure in 1 of them. Mean active flexion was $111^{\circ}$; strength was measured as 6 with Grade 4 and 2 with Grade 3. ${ }^{[14]}$

A retrospective study of the use of the latissimus dorsi muscle in seven patients of whom three were following brachial plexus injury showed post-operative Grade 4 in 5 , Grade 3 in 1 and Grade 2 in 1 patient with a mean active ROM of $91^{\circ}$; three of the patients with brachial plexus injury had a ROM of $0^{\circ}-90^{\circ}, 10^{\circ}-90^{\circ}$ and $0^{\circ}-20^{\circ}$, respectively; even this result was possible because of the technique of dual insertion at the biceps tendon and the proximal ulnar bone. The authors conclude that the results are good in patients with loss of anterior compartment musculature and not brachial plexus injury. ${ }^{[15]}$

The pectoralis major transfer takes advantage of the fact that the different parts of the muscle are innervated by branches of the upper and lower parts of the brachial plexus. The muscle length may need to be extended by a fascia or tendon graft; it was described originally by Brooks and Seddon, a recent paper published results of an average of $60^{\circ}$ of active elbow flexion. ${ }^{[16]}$

Steindler flexorplasty involves transferring the superficial common finger flexor origin onto the anterior surface of the humerus to restore elbow flexion; a flexion deformity of the elbow is inevitable and the absence of wrist extension preoperatively decreases the chance of a good result. ${ }^{[17]}$ A study of 12 patients with C5, 6, 7 injury showed that 10 had good or very good elbow flexion, but 10 of 12 had no elbow extension and this was achieved by a simultaneous wrist arthrodesis; this procedure is recommended in the absence of a functioning triceps. ${ }^{[18]}$

The whole triceps transfer was first described by Carroll and Hill and the transfer was used for mixed indications such as arthrogryosis and poliomyelitis in 15 patients..$^{10]}$ Complete transfer of the triceps causes loss of elbow extension which is important if the patient has a range of active shoulder abduction.

From the results of another study on 11 cases of upper plexus injuries with MRC Grade 4 in 8 MRC Grade 3 in 2 and Grade 2 in 1 ; the entire triceps was used, but there was no mention about the loss of active elbow extension. ${ }^{[19]}$

In a series of fifty patients using multiple techniques of transfer for elbow flexion in upper brachial plexus injury, the authors did 19 triceps transfers - 7 primarily due to delay in presentation and 12 secondary using muscle that had been reinnervated by previous nerve surgeries causing biceps-triceps cocontraction; 9 had very good $\left(>120^{\circ}\right.$, Grade 4$), 8$ had $\operatorname{good}\left(80^{\circ}-120^{\circ}\right.$ Grade 4$)$ and 1 fair $\left(80^{\circ}-120^{\circ}\right.$ Grade 3); there was 1 failure $\left(<80^{\circ}\right.$ and/or Grade 3). ${ }^{[4]}$ The technique of triceps transfer is not described, but it is assumed that the whole muscle was transferred on account of the indication of cocontraction.

There were ten patients in this study; seven of ten had at least antigravity biceps function [Table 1 and Figures 7-10]; on functional assessment using both ROM and strength seven of ten had good or very good function; in three of ten, the results were of no functional use. One of the three had poor tensioning, one had adhesions on account of post-operative haematoma and subsequent poor active ROM therapy and in one there was an inability to learn the rehabilitation process (this was the oldest case 


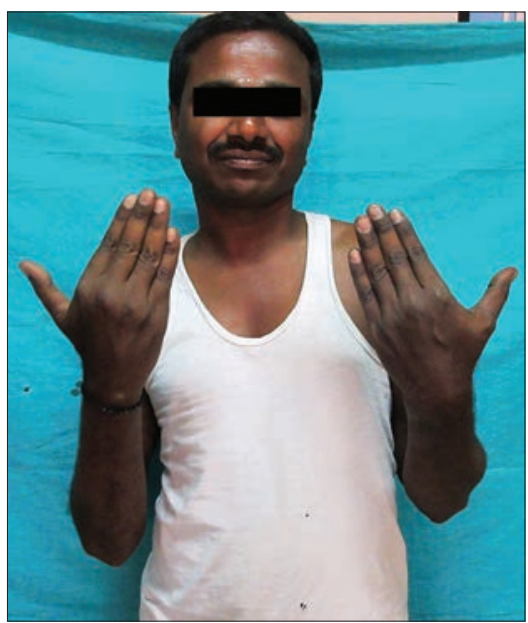

Figure 7: Post-operative follow-up showing flexion of elbow

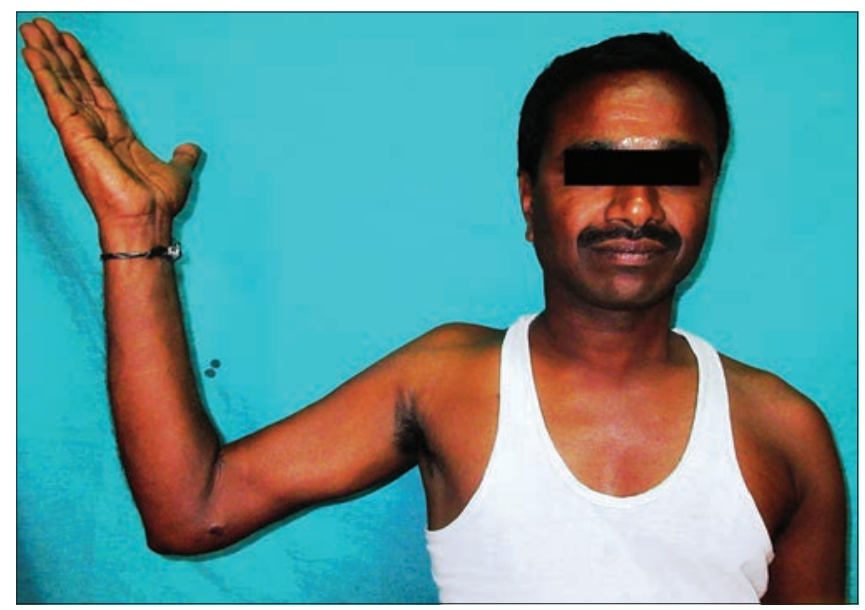

Figure 9: Post-operative follow-up showing elbow flexion

Table 2: Evaluation of the difference in elbow extension following surgery

\begin{tabular}{lcc}
\hline \multirow{2}{*}{ Serial number } & \multicolumn{2}{c}{ MRC grade } \\
\cline { 2 - 3 } & Pre-operative & Post-operative \\
\hline 1 & $5 / 5$ & $3 / 5$ \\
2 & $4 / 5$ & $3 / 5$ \\
3 & $4 / 5$ & $2 / 5$ \\
4 & $4 / 5$ & $2 / 5$ \\
5 & $4 / 5$ & $3 / 5$ \\
6 & $4 / 5$ & $3 / 5$ \\
7 & $4 / 5$ & $2 / 5$ \\
8 & $5 / 5$ & $3 / 5$ \\
9 & $5 / 5$ & $3 / 5$ \\
10 & $4 / 5$ & $3 / 5$ \\
\hline
\end{tabular}

Seven of ten cases had antigravity extension of the elbow. MRC: Medical Research Council

in the series 57 years). Seven out of ten patients retained Triceps power of MRC grade 3. Three patients retained power of 2 [Table 2].

Two of the ten patients in the present series underwent post-operative electroneuromyography study and did Indian Journal of Plastic Surgery Volume 50 Issue 1 January-April 2017

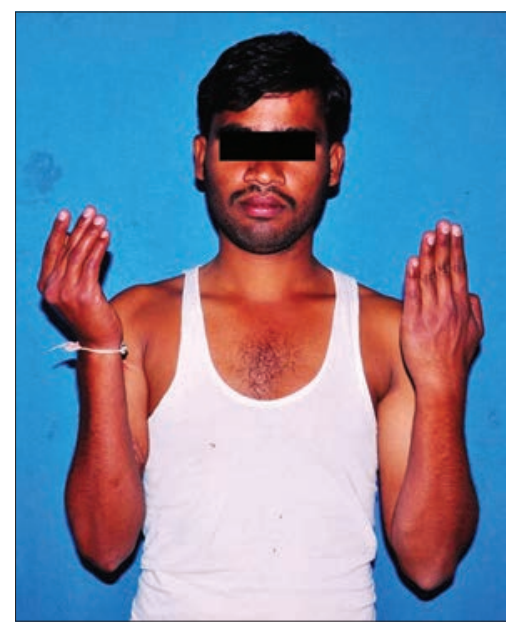

Figure 8: Patient 2: Post-operative follow-up showing flexion of elbow

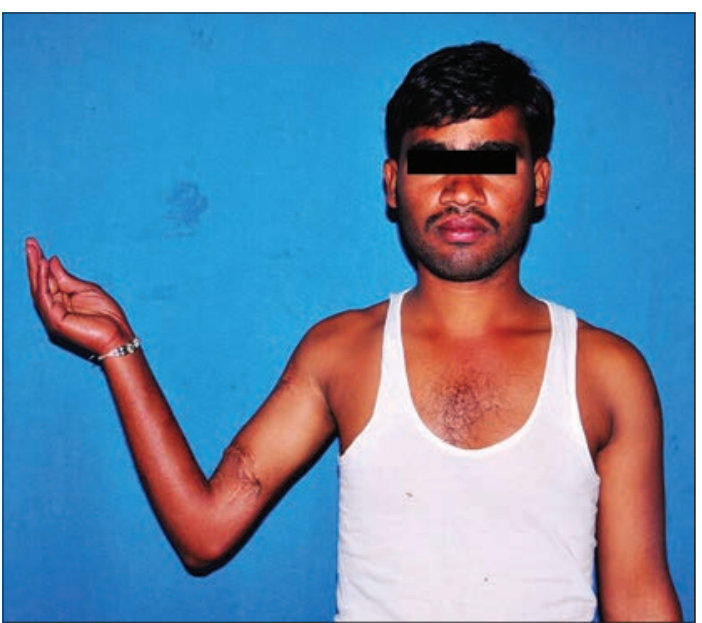

Figure 10: Patient 2: Post-operative follow-up showing elbow flexion

demonstrate the dissociation of elbow flexion from extension (electrical silence in the native triceps during active elbow flexion using the transferred triceps) [Figures 11 and 12].

Haninec and Szeder and later Ayemeric Lim described the use of the isolated long head of triceps for restoration of elbow flexion in a post-replant upper limb with return of Grade 4 elbow flexion; the retaining of elbow extension, the authors say it as important, especially in patients with normal shoulder abduction. ${ }^{[20,21]}$

In addition, the use of the long head may imply independent control of elbow flexion since it has a separate cortical representation and this can permit the dissociation of elbow flexion and extension in post-operative rehabilitation. ${ }^{[22]}$ Active ROM exercises not only permit regaining elbow flexion but also activate elbow extension [Figures 13 and 14]. 


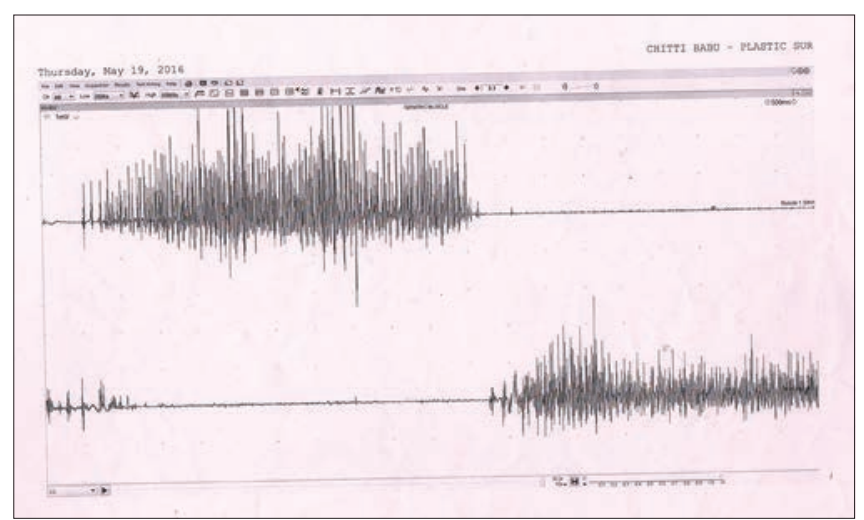

Figure 11: Post-operative follow-up electroneuromyography showing disassociation of electrical potentials between transferred head of triceps and native triceps. Native triceps is electrically silent when the transferred head of triceps is firing during elbow flexion

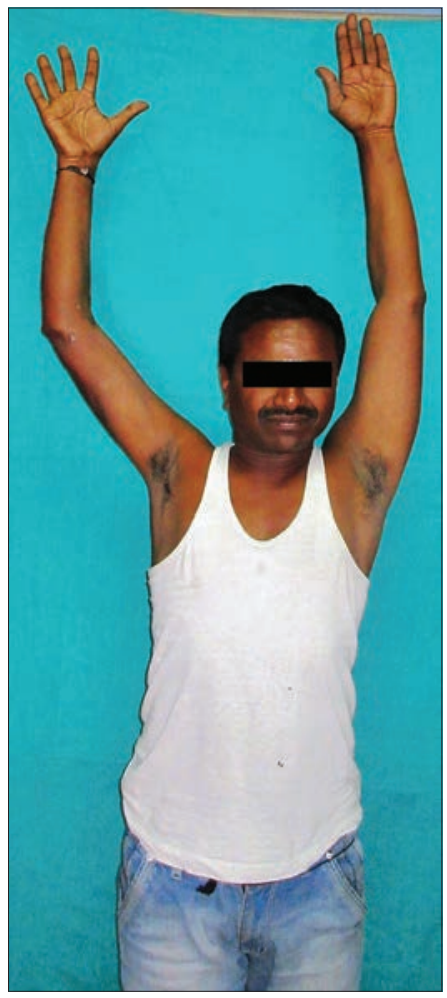

Figure 13: Post-operative follow-up showing elbow extension against gravity

\section{CONCLUSION}

Restoration of elbow flexion can be achieved through transfer of one head of triceps to biceps; the technique is simple, there is predictable return of elbow flexion and permits retaining active elbow extension. The EMNG study demonstrates that dissociation of elbow flexion from extension is possible, at least in young patients.

\section{Declaration of patient consent}

The authors certify that they have obtained all appropriate patient consent forms. In the form the patient(s) has/have

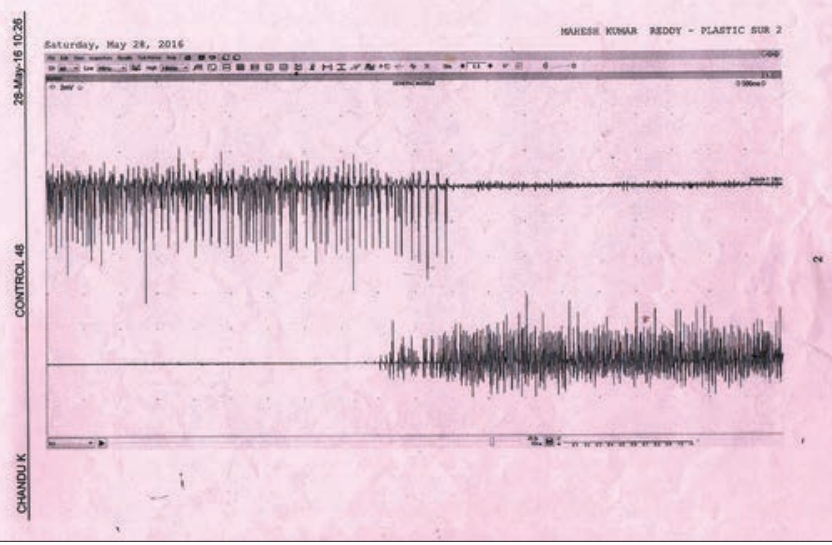

Figure 12: Patient 2: Post-operative follow-up with electroneuromyography showing the disassociation between the transferred head of triceps and native triceps

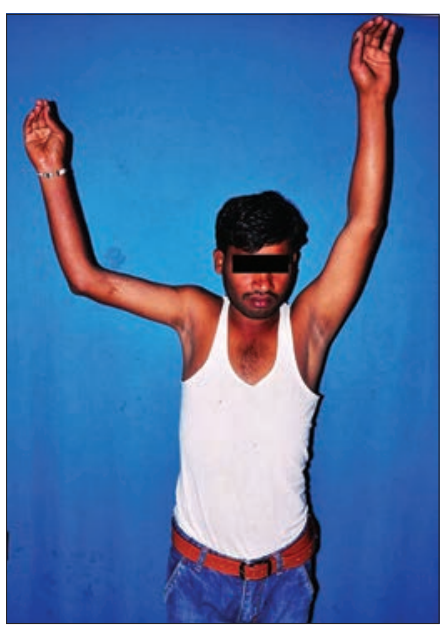

Figure 14: Patient 2: Post-operative follow-up showing elbow extension against gravity

given his/her/their consent for his/her/their images and other clinical information to be reported in the journal. The patients understand that their names and initials will not be published and due efforts will be made to conceal their identity, but anonymity cannot be guaranteed.

\section{Financial support and sponsorship}

Nil.

\section{Conflicts of interest}

There are no conflicts of interest.

\section{REFERENCES}

1. Vekris MD, Beris AE, Lykissas MG, Korompilias AV, Vekris AD, Soucacos PN. Restoration of elbow function in severe brachial plexus paralysis via muscle transfers. Injury 2008;39 Suppl 3:S15-22.

2. Chuang DC, Epstein MD, Yeh MC, Wei FC. Functional restoration of elbow flexion in brachial plexus injuries: Results in 
167 patients (excluding obstetric brachial plexus injury). J Hand Surg Am 1993;18:285-91.

3. Oberlin C, Béal D, Leechavengvongs S, Salon A, Dauge MC, Sarcy JJ. Nerve transfer to biceps muscle using a part of ulnar nerve for C5-C6 avulsion of the brachial plexus: Anatomical study and report of four cases. J Hand Surg Am 1994;19:232-7.

4. Rostoucher P, Alnot JY, Touam C, Oberlin C. Tendon transfers to restore elbow flexion after traumatic paralysis of the brachial plexus in adults. Int Orthop 1998;22:255-62.

5. Barrie KA, Steinmann SP, Shin AY, Spinner RJ, Bishop AT. Gracilis free muscle transfer for restoration of function after complete brachial plexus avulsion. Neurosurg Focus 2004;16:E8.

6. Schottstaedt ER, Larsen LJ, Bost FC. Complete muscle transposition. J Bone Joint Surg Am 1955;37-A: 897-918.

7. Steindler A. Tendon transplantation in the upper extremity. Am J Surg 1939;XLIV: 260-71.

8. Clark JM. Reconstruction of biceps brachii by pectoral muscle transplantation. Br J Surg 1946;34:180.

9. Brooks DM, Seddon HJ. Pectoral transplantation for paralysis of the flexors of the elbow; a new technique. J Bone Joint Surg $\mathrm{Br}$ 1959;41-B: 36-43.

10. Carroll RE, Hill NA. Triceps transfer to restore elbow flexion. Astudy of fifteen patients with paralytic lesions and arthrogryposis. J Bone Joint Surg Am 1970;52:239-44.

11. Madsen M, Marx RG, Millett PJ, Rodeo SA, Sperling JW, Warren RF. Surgical anatomy of the triceps brachii tendon: Anatomical study and clinical correlation. Am J Sports Med 2006;34:1839-43.

12. Moursy M, Cafaltzis K, Eisermann S, Lehmann LJ. Latissimus dorsi transfer: L'Episcopo versus Herzberg technique. Acta Orthop Belg 2012;78:296-303. De Smet L. Bipolar latissimus dorsi flap transfer for reconstruction of the deltoid. Acta Orthop
Belg 2009;75:32-6.

13. Chaudhry S, Hopyan S. Bipolar latissimus transfer for restoration of elbow flexion. J Orthop 2013;10:133-8.

14. Kawamura K, Yajima H, Tomita Y, Kobata Y, Shigematsu K, Takakura Y. Restoration of elbow function with pedicled latissimus dorsi myocutaneous flap transfer. J Shoulder Elbow Surg 2007;16:84-90.

15. Cambon-Binder A, Belkheyar Z, Durand S, Rantissi M, Oberlin C. Elbow flexion restoration using pedicled latissimus dorsi transfer in seven cases. Chir Main 2012;31:324-30.

16. Hierner R, Berger A. Pectoralis major muscle transfer for reconstruction of elbow flexion in posttraumatic brachial plexus lesions. Oper Orthop Traumatol 2009;21:126-40.

17. Mayer L, Green W. Experiences with the Steindler flexorplasty at the elbow. J Bone Joint Surg Am 1954;36-A:775-89.

18. Monreal R. Steindler flexorplasty to restore elbow flexion in C5-C6-C7 brachial plexus palsy type. J Brachial Plex Peripher Nerve Inj 2007;2:15.

19. Souza FI, Saito M, Kimura LK, Júnior RM, Zumiotti AV. Muscle transfer from triceps to biceps in patients with chronic injury of the upper trunk of the brachial plexus. Rev Bras Ortop 2015;45:409-12.

20. Haninec P, Szeder V. Reconstruction of elbow flexion by transposition of pedicled long head of triceps brachii muscle. Acta Chir Plast 1999;41:82-6.

21. Naidu S, Lim A, Poh LK, Kumar VP. Long head of the triceps transfer for elbow flexion. Plast Reconstr Surg 2007;119:45e-47e.

22. Lucas-Osma AM, Collazos-Castro JE. Compartmentalization in the triceps brachii motoneuron nucleus and its relation to muscle architecture. J Comp Neurol 2009;516:226-39. 